\title{
PEMODELAN MOTIF KERAMIK DENGAN TEKNIK PENGGABUNGAN BANGUN-BANGUN GEOMETRI DATAR DENGAN KONSEP TRANSFORMASI
}

\author{
Dzurotul Mutimmah ${ }^{1}$, Puput Bahtiar Rifa'i ${ }^{2}$ \\ ${ }^{1,2}$ Universitas PGRI Banyuwangi \\ Email:dzurotulmutimmah69@gmail.com ${ }^{1)}$, puputbahtiarrifai@gmail.com ${ }^{2)}$
}

\begin{abstract}
The objectives of this research are to obtain the procedure of ceramic motif design with through merging some objects flat geometry by concept of transformation, thus, it product a ceramic motif design that both varied and innovative. In terms geometry, ceramic motif design still monotone and built of one or two objects geometry. The research method covered the ceramic motif design with axis symmetry pattern and central symmetry pattern. The results of this research are the procedure of ceramic motif design and variation with the following steps. First, design the ceramic motif with axis symmetry pattern and central symmetry pattern based on square and split it into two or four part. Second, fill the one of part square with triangle and circle. Third, transform the contents of part to the other parts. Finally, we simulate the design of ceramic motif by using computer software Maple 12.
\end{abstract}

Keywords: Ceramic, An Isosceles Triangle, Square, Circle.

\section{PENDAHULUAN}

Lantai adalah bagian dari ruang interior yang merupakan unsur bagian dasar suatu ruang serta penutup ruang bagian bawah yang berfungsi menjadi pemikul beban atau benda yang berada diatasnya baik benda mati seperti furniture, aksesoris, maupun benda hidup berupa aktivitas manusia (Mangunwijaya: 1980 dalam Dewi 2014). Salah satu material penutup lantai, yaitu keramik. Keramik merupakan bahan material bangunan dan terbuat dari tanah liat yang dipanaskan. Saat ini, keramik merupakan jenis penutup lantai yang paling popular digunakan oleh masyarakat. Dengan pemasangan keramik pada lantai rumah, ruangan akan tampak lebih indah. Keramik mempunyai dua macam permukaan, yaitu keramik dengan permukaan kasar dan permukaan halus. Keramik dengan permukaan kasar biasanya digunakan di tempat-tempat basah. Sedangkan keramik dengan permukaan halus digunakan di tempat kering.

Jika dibandingkan dengan penutup lantai yang lain, seperti plester dan marmer, keramik masih memiliki keunggulan. Kelemahan plester, yaitu jika retak tidak dapat diganti, tetapi hanya bisa ditambal. Sedangkan kelemahan marmer yaitu memiliki poripori yang relatif besar dan membutuhkan perawatan ekstra (Jannah, 2014). Dari kelemahan kedua jenis penutup lantai tersebut, keramik dapat mengatasi kekurangannya, yaitu jika keramik retak, maka keramik tersebut dapat diganti persatuan. Keramik juga memiliki permukaan dengan pori-pori rapat sehingga perawatannya lebih mudah. Selain itu, keramik mempunyai daya tertentu atas hasil uji coba yang sangat baik untuk kegunaan dan kenyamanan konsumen sehingga keberadaannya tersebut di buat 
sedemikian rupa menjadi lebih kuat (Maulana, 2015).

Setiap keramik mempunyai corak atau motif yang berbeda-beda. Saat ini, keramik yang beredar dipasaran mempunyai berbagai macam motif seperti Gambar 1. Namun, dari segi geometri terdapat beberapa kelemahan pada keramik tersebut, yaitu desain motif keramik masih monoton karena hanya terdiri dari satu atau dua bangun datar saja.

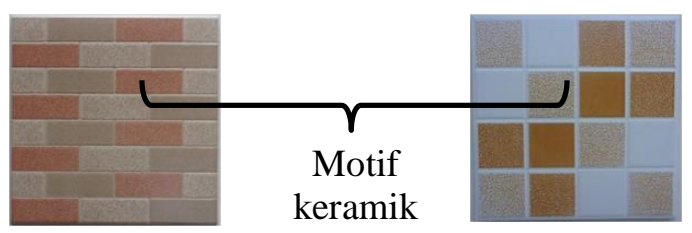

Gambar 1 Beberapa desain motif keramik

Sehubungan dengan permasalahan diatas, penelitian ini dimaksudkan untuk memodelisasi motif keramik dengan penggabungan bangun-bangun geometri datar dengan konsep transformasi, yang terkomposisi dari bangun datar persegi, segitiga, dan lingkaran. Alasan pemilihan bangun-bangun geometri datar tersebut, yaitu dari bangun datar sederhana dapat di modelisasi menjadi motif keramik yang bervariasi dan inovatif.

Misalkan diberikan dua buah titik $A\left(x_{A}, y_{A}\right)$ dan $B\left(x_{B}, y_{B}\right)$ di bidang $X O Y$. Melalui kedua data titik tersebut dibangun sebuah persegi $A B C D$ dengan cara, pertama, dibangun segmen garis $\overline{A B}$ dengan formula:

$(1-\lambda)\left\langle x_{1}, y_{1}\right\rangle+\lambda\left\langle x_{2}, y_{2}\right\rangle=\langle x, y\rangle$.

(1) Kemudian dihitung koordinat titik $C$ dan titik $D$ melalui persamaan $\overrightarrow{O C}=$ $\left(\overrightarrow{O B}+k \boldsymbol{n}_{A B}\right)$ dan $\overrightarrow{O D}=\left(\overrightarrow{O A}+k \boldsymbol{n}_{A B}\right)$, dengan $\quad \boldsymbol{n}_{A B}=\frac{\left\langle\left(y_{B}-y_{A}\right),-\left(x_{B}-x_{A}\right)\right\rangle}{\sqrt{\left(x_{B}-x_{A}\right)^{2}+\left(y_{B}-y_{A}\right)^{2}}}$ merupakan normal satuan $\overrightarrow{A B}$ dan $k=$ $|\overline{A B}|$. Selanjutnya membangun segmen garis $\overline{B C}, \overline{C D}$, dan $\overline{A D}$ melalui persamaan (1) sehingga terbentuk persegi $A B C D$ (Mutimmah, 2014).

Misal diberikan dua buah titik sebarang $A\left(x_{1}, y_{1}\right)$ dan $B\left(x_{2}, y_{2}\right)$ di bidang $X O Y$. Melalui kedua data titik tersebut dibangun sebuah segitiga samakaki $A B C$ dengan cara sebagai berikut. Pertama, dibangun segmen garis $\overline{A B}$ melalui persamaan (1). Selanjutnya koordinat titik $M$ yang terletak di tengah-tengah segmen garis $\overrightarrow{A B}$ melalui persamaan $\overrightarrow{O M}=$ $\left(\overrightarrow{O A}+\frac{1}{2} \overrightarrow{A B}\right) . \quad$ Kemudian dihitung koordinat titik $C$ melalui persamaan $\overrightarrow{O C}=\left(\overrightarrow{O M}+k \boldsymbol{n}_{A B}\right) . \quad$ Selanjutnya membangun segmen garis $\overline{A C}$ dan $\overline{B C}$ melalui persamaan (1) sehingga terbentuk segitiga samakaki $A B C$ melalui teorema kekongruenan segitiga (S-Sd-S) (Mutimmah, 2012).

Lingkaran adalah himpunan titiktitik di bidang yang jaraknya terhadap titik tertentu tetap (Kusno, 2002). Titik tetap ini selanjutnya disebut pusat lingkaran. Jika $P(x, y)$ sebarang titik pada lingkaran berpusat di $O(0,0)$, $|\overrightarrow{O P}|=r$ dan $\angle P O Q=\theta$, maka bentuk persamaan parametrik lingkaran, yaitu:

$$
L(\theta)=\langle r \cos \theta, r \sin \theta\rangle .
$$

\section{METODE PENELITIAN}

Untuk memodelisasi motif keramik dengan bentuk dasar persegi menggunakan penggabungan bangunbangun geometri datar dengan konsep transformasi digunakan tahapan kegiatan penelitian sebagai berikut. Pertama, membagi persegi menjadi dua atau empat bagian. Kedua, mengisi bagian tersebut dengan bangun segitiga samakaki dan lingkaran. Ketiga, mentransformasikan hasil pengisian ke bagian lainnya. Keempat, menyusun program komputer hasil analisis menggunakan software Maple 12. 


\section{HASIL PENELITIAN DAN PEMBAHASAN \\ Modelisasi Motif Keramik}

\section{Pola Simetri Sumbu}

Prosedur untuk membangun motif keramik dengan pola simetri sumbu sebagai berikut:

1. Menetapkan dua buah titik $T_{1}$ dan $T_{2}$ di tengah segmen garis $\overline{P_{1} P_{4}}$ dan $\overline{P_{2} P_{3}}$ dan membangun segmen garis $\overline{T_{1} T_{2}}$ sehingga terbentuk dua bagian sama besar pada persegi $P_{1} P_{2} P_{3} P_{4}$ (Gambar 2).

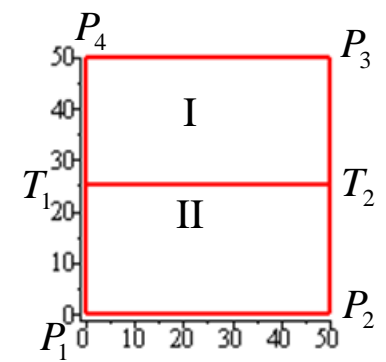

Gambar 2 Pembagian persegi $P_{1} P_{2} P_{3} P_{4}$ menjadi dua bagian

2. Mengisi bagian I dengan bangunbangun datar yaitu enam buah segitiga dan dua buah lingkaran dengan titik sebagai berikut.

a. Menetapkan titik $T_{3}$, kemudian membangun segmen garis $\overline{T_{2} T_{3}}$ sehingga terbentuk bangun segitiga $T_{1} T_{2} T_{3}$.

b. Menetapkan titik $T_{4}, T_{5}$, dan $T_{6}$, kemudian membangun segmen garis $\overline{T_{4} T_{5}}$ dan $\overline{T_{5} T_{6}}$ sehingga terbentuk bangun segitiga $T_{4} T_{5} T_{6}$.

c. Menetapkan titik $T_{7}, T_{8}$, dan $T_{9}$, kemudian membangun segmen garis $\overline{T_{7} T_{8}}, \overline{T_{8} T_{9}}$, dan $\overline{T_{9} T_{7}}$ sehingga terbentuk bangun segitiga $T_{7} T_{8} T_{9}$.

d. Menetapkan titik $T_{10}, T_{11}$, dan $T_{12}$, kemudian membangun segmen garis $\overline{T_{10} T_{11}}, \overline{T_{11} T_{12}}$, dan $\overline{T_{12} T_{10}}$ sehingga terbentuk bangun segitiga $T_{10} T_{11} T_{12}$.

e. Menetapkan titik $T_{13}$ dan $T_{14}$, kemudian membangun segmen garis $\overline{T_{13} T_{14}}, \overline{T_{14} T_{12}}$, dan $\overline{T_{12} T_{13}}$ sehingga terbentuk bangun segitiga $T_{12} T_{13} T_{14}$.

f. Menetapkan titik $T_{16}, T_{17}$, dan $T_{18}$, kemudian mebangun segmen garis $\overline{T_{16} T_{17}}, \overline{T_{17} T_{18}}$, dan $\overline{T_{18} T_{16}}$ sehingga terbentuk bangun segitiga $T_{16} T_{17} T_{18}$.

g. Membangun lingkaran dengan menentukan titik pusat di $C_{1}$ dan berjari-jari $2.7 \mathrm{~cm}$ (Gambar 3).

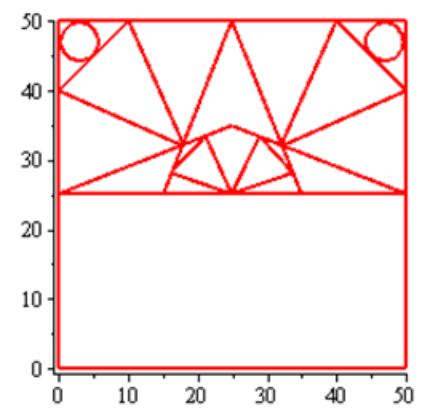

Gambar 3 Pengisian bagian I

3. Merefleksikan hasil pengisian bagian I terhadap garis $y=5$ sehingga didapat hasil modelisasi motif keramik seperti Gambar 4.

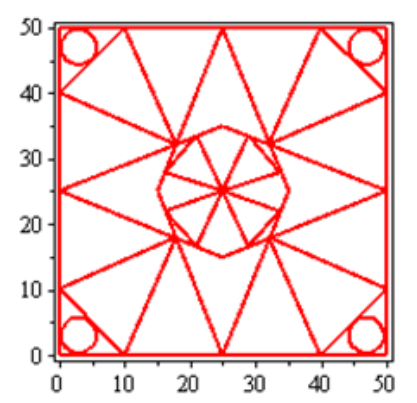

Gambar 4 Hasil refleksi bagian I ke bagian II

Adapun contoh motif keramik lain dengan pola simetri sumbu, yaitu dengan langkah-langkah seperti berikut.

1. Menetapkan empat titik $Z_{1}, Z_{2}, Z_{3}$, dan $Z_{4}$, kemudian membangun segmen garis $\overline{Z_{1} Z_{3}}$ dan $\overline{Z_{2} Z_{4}}$ (Gambar 5). 


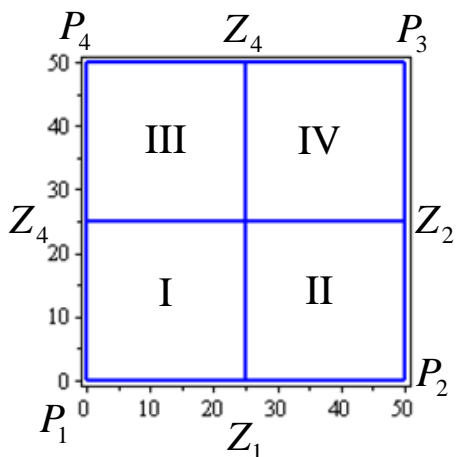

Gambar 5 Pembagian persegi $P_{1} P_{2} P_{3} P_{4}$ menjadi empat bagian

2. Kemudian membuat 3 buah segitiga dan sebuah lingkaran dengan titiktitik sebagai berikut.

a. Menetapkan titik $P_{5}, P_{6}$, dan $P_{7}$, kemudian membangun segmen garis $\overline{P_{5} P_{6}}, \overline{P_{6} P_{7}}$, dan $\overline{P_{7} P_{5}}$ sehingga terbentuk bangun segitiga $P_{5} P_{6} P_{7}$.

b. Menetapkan titik $P_{8}$ dan $P_{9}$, kemudian membangun segmen garis $\overline{P_{8} P_{9}}, \overline{P_{9} P_{6}}$, dan $\overline{P_{6} P_{9}}$ sehingga terbentuk bangun segitiga $P_{6} P_{8} P_{9}$.

c. Menetapkan titik $P_{10}$ dan $P_{11}$, kemudian membangun segmen garis $\overline{P_{10} P_{6}}, \overline{P_{6} P_{11}}$, dan $\overline{P_{11} P_{10}}$ sehingga terbentuk bangun segitiga $P_{6} P_{10} P_{11}$.

d. Membangun lingkaran dengan titik pusat di $L_{1}$ dan berjari-jari $r=3.5 \mathrm{~cm}$ (Gambar 6).

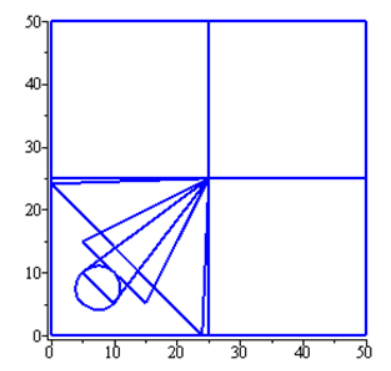

Gambar 6 Hasil pengisian bagian I

3. Merefleksikan hasil pengisian bagian I ke bagian II, bagian II ke bagian III, dan bagian III ke bagian IV (Gambar 7).

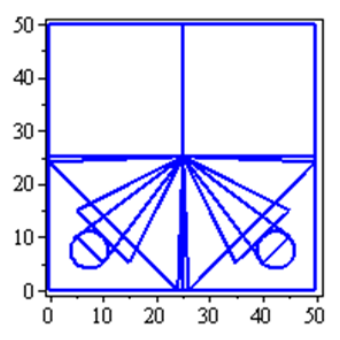

(a)

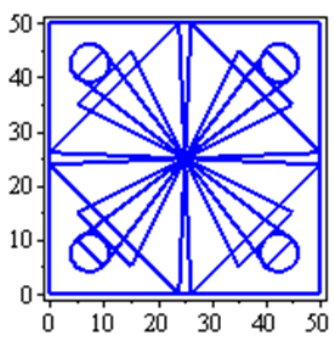

(b)
Gambar 7 Hasil refleksi bagian I ke bagian II, III, dan IV

Adapun validasi beberapa hasil modelisasi motif keramik dengan pola simetri sumbu yaitu seperti Gambar 8 di bawah ini.

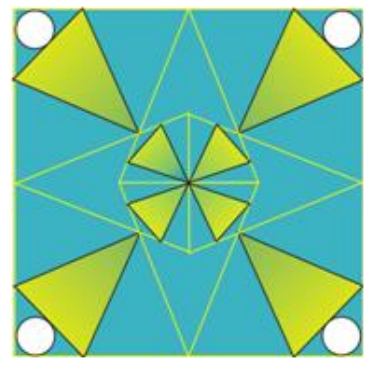

(a)

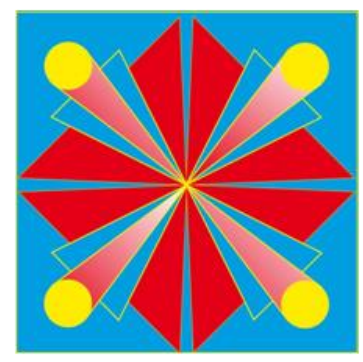

(b)
Gambar 8 Validasi beberapa motif keramik pola simetri sumbu

\section{Modelisasi Motif Keramik}

\section{Pola Simetri Pusat}

Prosedur untuk membangun motif keramik dengan pola simetri pusat sebagai berikut:

1. Membangun segmen garis $\overline{P_{1} P_{3}}$ sehingga terdapat empat bagian segitiga sama besar (Gambar 9).

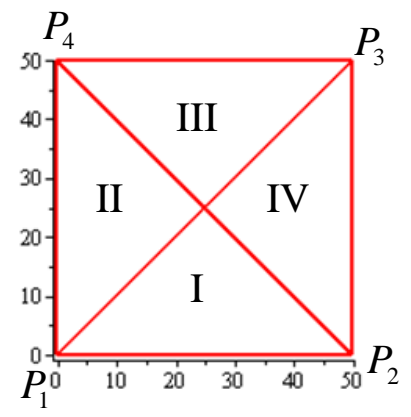

Gambar 9 Pembagian persegi $P_{1} P_{2} P_{3} P_{4}$ menjadi empat bagian 
2. Mengisi bagian I dengan bangun geometri datar yang terkomposisi dari sembilan segitiga dan dua lingkaran sebagai berikut.

a. Menetapkan titik $A_{1}, A_{2}$, dan $A_{3}$, kemudian membangun segmen garis $\overline{A_{1} A_{2}}, \overline{A_{2} A_{3}}$ dan $\overline{A_{3} A_{1}}$ sehingga terbentuk bangun segitiga $A_{1} A_{2} A_{3}$.

b. Menetapkan titik $A_{4}$ dan $A_{5}$, kemudian membangun segmen garis $\overline{A_{3} A_{4}}, \overline{A_{4} A_{5}}$ dan $\overline{A_{5} A_{3}}$ sehingga terbentuk bangun segitiga $A_{3} A_{4} A_{5}$.

c. Menetapkan titik $A_{6}$ dan $A_{7}$, kemudian membangun segmen garis $\overline{A_{5} A_{6}}, \overline{A_{6} A_{7}}$ dan $\overline{A_{7} A_{5}}$ sehingga terbentuk bangun segitiga $A_{5} A_{6} A_{7}$.

d. Menetapkan titik $A_{8}$ kemudian membangun segmen garis $\overline{A_{8} A_{6}}$, $\overline{A_{8} A_{1}}$ dan $\overline{A_{1} A_{6}}$ sehingga terbentuk bangun segitiga $A_{1} A_{6} A_{8}$.

e. Menetapkan titik $A_{9}, A_{10}$ dan $A_{11}$, kemudian membangun segmen garis $\overline{A_{9} A_{10}}, \overline{A_{10} A_{11}}$ dan $\overline{A_{11} A_{9}}$ sehingga terbentuk bangun segitiga $A_{9} A_{10} A_{11}$.

f. Menetapkan titik $A_{12}$ dan $A_{13}$, kemudian membangun segmen garis $\overline{A_{12} A_{13}}, \overline{A_{12} P_{1}}$ dan $\overline{P_{1} A_{12}}$ sehingga terbentuk bangun segitiga $A_{12} A_{13} P_{1}$.

g. Menetapkan titik $A_{14}$ dan $A_{15}$, kemudian membangun segmen garis $\overline{A_{14} A_{15}}, \overline{A_{15} P_{2}}$ dan $\overline{P_{2} A_{14}}$ sehingga terbentuk bangun segitiga $A_{14} A_{15} P_{2}$.

h. Menetapkan titik $A_{16}$ dan $A_{17}$, kemudian membangun segmen garis $\overline{A_{16} A_{17}}, \overline{A_{17} P_{1}}$ dan $\overline{P_{1} A_{16}}$ sehingga terbentuk bangun segitiga $A_{16} A_{17} P_{1}$.

i. Menetapkan titik $A_{18}$ dan $A_{19}$, kemudian membangun segmen garis $\overline{A_{18} A_{19}}, \overline{A_{19} P_{2}}$ dan $\overline{P_{2} A_{18}}$ sehingga terbentuk bangun segitiga $A_{18} A_{19} P_{2}$.

j. Membangun 2 buah lingkaran dengan menentukan titik pusat $L_{1}$ dengan jari-jari yang berbeda, yaitu $C_{1}=8$ dan $C_{2}=7$.

3. Merotasikan hasil pengisian bagian I ke bagian II, III, dan IV dengan besar sudut rotasi masing-masing mulai $90^{\circ}, 180^{\circ}$, dan $270^{\circ}$ (Gambar $10)$.

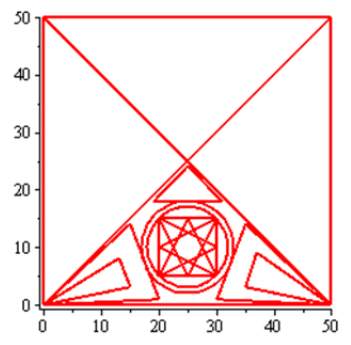

(a)

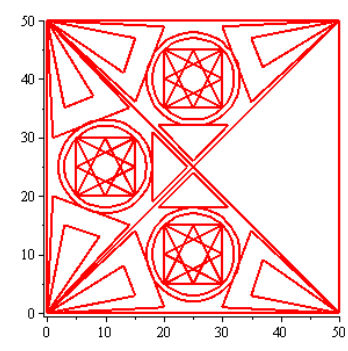

(c)

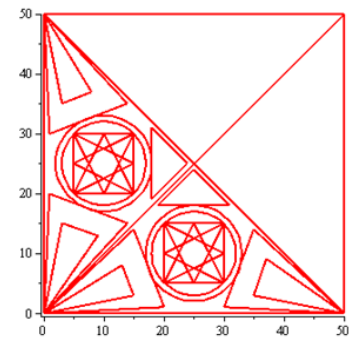

(b)

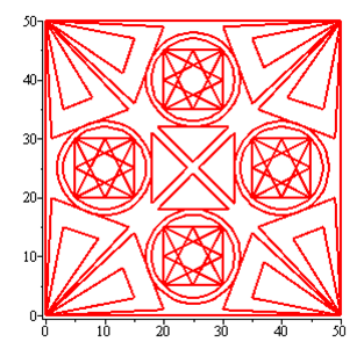

(d)
Gambar 10 Langkah-langkah modelisasi motif keramik pola simetri pusat

Adapun contoh motif keramik lain dengan motif simetri pusat, yaitu dengan langkah-langkah sebagai berikut.

1. Menetapkan $P_{5}, P_{6}, P_{7}$, dan $P_{8}$, kemudian membangun segmen garis $\overline{P_{1} P_{3}}, \overline{P_{2} P_{4}}, \overline{P_{5} P_{7}}$, dan $\overline{P_{6} P_{8}}$ seperti pada Gambar 11 . 


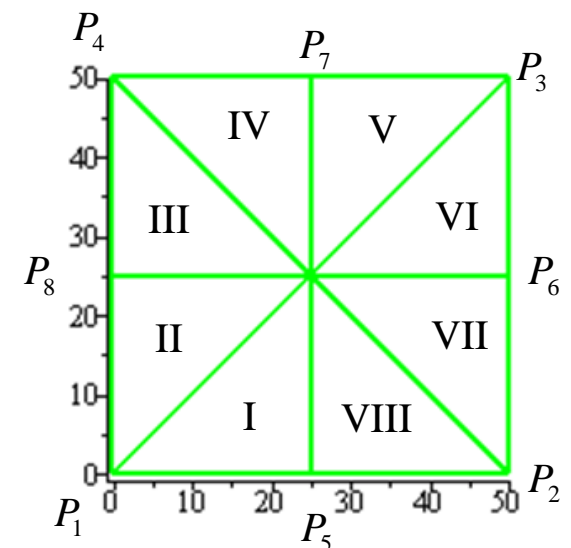

Gambar 11 Delapan bagian persegi

$$
P_{1} P_{2} P_{3} P_{4}
$$

2. Mengisi bagian I dengan bangun datar segitiga dan lingkaran. Selanjutnya merotasikan hasil pengisian bagian I ke bagian II hingga bagian VIII dengan besar sudut rotasi masing-masing mulai $45^{\circ}, 90^{\circ}, 135^{\circ}, 180^{\circ}, 225^{\circ}, 270^{\circ}$ dan $315^{\circ}$ (Gambar 12).

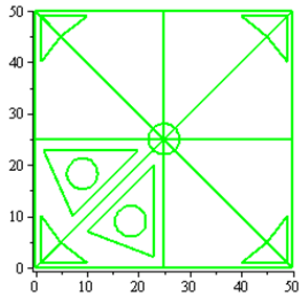

(a)

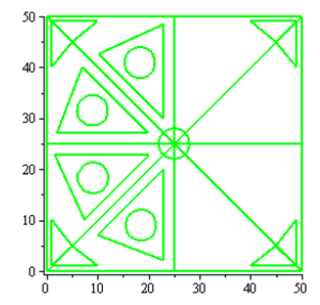

(c)

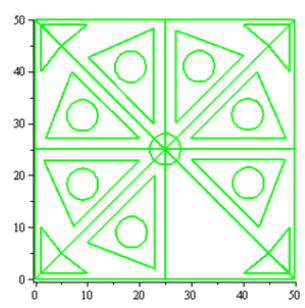

(e)

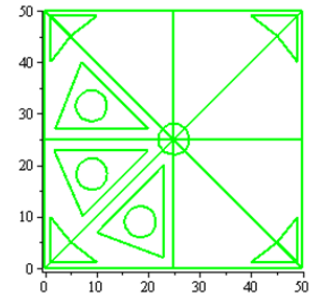

(b)

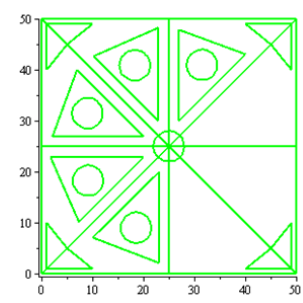

(d)

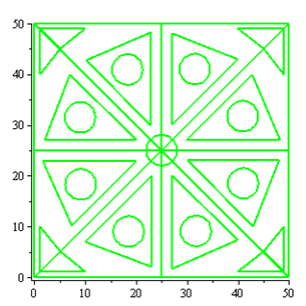

(f)
Gambar 12 Pengisian bagian-bagian persegi dengan konsep rotasi
Adapun validasi beberapa hasil modelisasi motif keramik dengan pola simetri pusat yaitu seperti Gambar 13 di bawah ini.

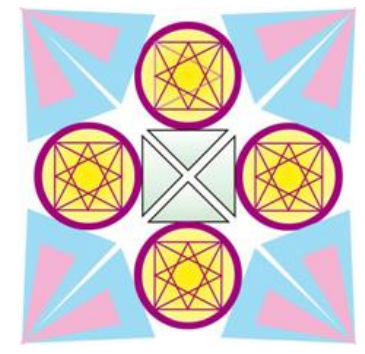

(a)

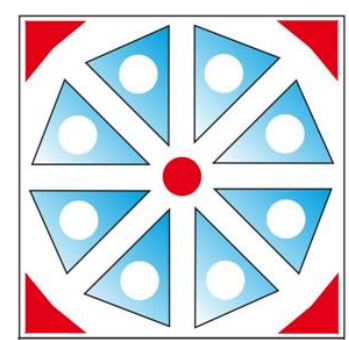

(b)
Gambar 13 Validasi beberapa motif keramik pola simetri pusat

\section{KESIMPULAN DAN SARAN}

Berdasarkan hasil penelitian di atas, didapatkan kesimpulan langkahlangkah memodelisasi motif keramik dengan bangun dasar persegi terkomposisi dari penggabungan bangun-bangun geometri datar segitiga dan lingkaran, yaitu sebagai berikut:

a. pola simetri sumbu

- membagi persegi menjadi dua bagian;

- mengisi bagian-bagian tersebut dengan bangun-bangun geometri datar segitiga dan lingkaran;

b. pola simetri pusat

- membagi persegi menjadi empat bagian;

- mengisi bagian-bagian tersebut dengan bangun-bangun geometri datar segitiga dan lingkaran.

Adapun saran dalam penelitian ini yaitu dapat di bangun motif-motif keramik dengan bangun geometri datar lainnya, seperti elips, segilima, dan segienam.

\section{DAFTAR PUSTAKA}

Dewi, Ni N.E.M., 2014. Kajian Interior Elemen Pembentukan dan Pelengkap Pembentuk Ruang. 
ISSN 2089-8703 (Print) Vol. 6, No. 3 (2017)

ISSN 2442-5419 (Online)

Jurnal Desain Interior. Vol. 1, No. 1, Hal 1-17.

Jannah, R. M. 2014. Wordpress. Retrieved 08 06, 2017, from https://ryanimj.wordpress.com/20 14/10/11/ubin-dan-keramik

Kusno. 2002. Geometri Rancang Bangun Studi Aljabar Vektor Garis, Lingkaran dan Ellips. Jember: Jurusan Matematika Fakultas MIPA Universitas Jember.

Maulana, D. 2015. Pemanfaatan Limbah Keramik (Tile) untuk Pengembangan Produk Elemen Mosaic Pada Dinding. Jurnal Universitas Pembangunan Jaya. Vol. 2. Hal 117-125.

Mutimmah, D. 2012. Modelisasi Liontin Kalung dan Anting. Skripsi. Jember: Jurusan Matematika Fakultas MIPA Universitas Jember.

Mutimmah, D. 2014. Modelisasi Lampion dengan Penggabungan Kerangka Bangun Geometri Ruang dan Lipatan Bidang. Tesis. Jember: Jurusan Matematika Fakultas MIPA Universitas Jember. 